\title{
Simultaneous determination of three sulfanilamide artificial sweeteners in foodstuffs by capillary electrophoesis coupled with contactless conductivity detection based on porous aromatic frameworks enhanced solid phase extraction
}

\begin{tabular}{|c|c|}
\hline Journal: & Canadian Journal of Chemistry \\
\hline Manuscript ID & cjc-2018-0410 \\
\hline Manuscript Type: & Article \\
\hline $\begin{array}{l}\text { Date Submitted by the } \\
\text { Author: }\end{array}$ & 26-Sep-2018 \\
\hline Complete List of Authors: & $\begin{array}{l}\text { Xia, Shaige; Zhengzhou University, College of Chemistry and Molecular } \\
\text { Engineering } \\
\text { Yin, Dan; Zhengzhou University, College of Chemistry and Molecular } \\
\text { Engineering } \\
\text { Chen, Yanlong; Zhengzhou University, College of Chemistry and } \\
\text { Molecular Engineering } \\
\text { Yang, Zhicong; Zhengzhou University, College of Chemistry and } \\
\text { Molecular Engineering } \\
\text { Miao, Ying; Zhengzhou University, College of Chemistry and Molecular } \\
\text { Engineering } \\
\text { Zhang, Wenfen; Zhengzhou University, College of Chemistry and } \\
\text { Molecular Engineering } \\
\text { Chen, Sheng; Zhengzhou University, College of Chemistry and Molecular } \\
\text { Engineering; Zhengzhou University, Center for Advanced Analysis and } \\
\text { Computational Science } \\
\text { Zhao, Wuduo; Zhengzhou University, College of Chemistry and Molecular } \\
\text { Engineering; Zhengzhou University, Center for Advanced Analysis and } \\
\text { Computational Science } \\
\text { Zhang, Shusheng; Zhengzhou University, College of Chemistry and } \\
\text { Molecular Engineering; Zhengzhou University, Center for Advanced } \\
\text { Analysis and Computational Science }\end{array}$ \\
\hline $\begin{array}{r}\text { Is the invited manuscript for } \\
\text { consideration in a Special } \\
\text { Issue?: }\end{array}$ & Not applicable (regular submission) \\
\hline Keyword: & $\begin{array}{l}\text { porous aromatic frameworks, solid phase extraction, sulfanilamide } \\
\text { artificial sweeteners, foodstuffs }\end{array}$ \\
\hline
\end{tabular}

\section{SCHOLARONE ${ }^{m}$ Manuscripts}


1 Simultaneous determination of three sulfanilamide artificial sweeteners in foodstuffs by capillary electrophoesis coupled with contactless conductivity detection based on porous aromatic frameworks enhanced solid phase extraction

13 *Corresponding authors at:

14 Shusheng Zhang, Email: zsssz@126.com; Phone: +86-0371-67739686.

15 Wuduo Zhao,Email: zhaowuduo@163.com 


\section{Abstract}

In this paper, a simple and easy-operating method of solid phase extraction (SPE) followed by capillary

20 approach for the simultaneously determination of acesulfame-K (ACE), sodium saccharin (SAC) and sodium

21 cyclamate (CYC) in foodstuffs without derivatization. In order to reduce the complex matrix interference resulting

22 from the constituents of samples and enrich targets, porous aromatic frameworks (PAFs) enhanced SPE, a suitable

23 sample pretreatment procedure was introduced. Several factors affecting extraction efficiency and electrophoretic

24 separation were investigated. Additionally, The interaction mechanisms of host (PAF-6)-guests (ACE/SAC/CYC)

25 were further studied. Under the optimum conditions, three sulfanilamide artificial sweeteners were baseline separated

26 within 8 min, exhibiting a linear calibration over three orders of magnitude $\left(\mathrm{R}^{2}>0.995\right)$; The limits of detection (LOD)

27 and quantification (LOQ) were considered better than those usually obtained by CE with UV and $\mathrm{C}^{4} \mathrm{D}$ detection. The

28 proposed SPE-CE-C ${ }^{4}$ D method has been successfully applied to analyse beverage samples and candied fruits with

29 recoveries in the range of $78.89-92.00 \%$.

30 Keywords: porous aromatic frameworks; solid phase extraction; sulfanilamide artificial sweeteners; foodstuffs; 


\section{Introduction}

High-intensity sweeteners can be divided into natural sweeteners and synthetic sweeteners according to their

source ${ }^{1}$. Sweeteners have been widely used in foodstuffs since entering the food industry back in the 1800 's ${ }^{2}$, especially artificial high-intensity sweeteners with low calorie. In these so-called non-nutritive sweeteners, acesulfame-K (ACE), sodium saccharin (SAC) and sodium cyclamate (CYC) (Fig. 1B) are mostly common artificial synthetic sweeteners to replace sugar in foods in order to guarantee the safety and good quality of foods, as well as satisfy the needs of consumers, particularly individuals with obesity and diabetes mellitus. Therefore, the consumption of these low-calories foods by the worldwide population has dramatically increased. And it brings the suspicions of adverse health effects of artificial high-intensity sweeteners. The study reported that continuous ingestion of these sweeteners can lead to a metabolic disorder ${ }^{3,4}$. To assure food safety, the World Health Organization (WHO) has placed strictest restriction on its usage and its acceptable daily intake (ADI) value ${ }^{5}$, and many countries have also enacted relevant legislations ${ }^{6-8}$. For the determination of individual sweeteners and their combinations, several analytical methods have been proposed including high-performance liquid chromatography 
50 CE-C ${ }^{4} \mathrm{D}{ }^{28-30}$ methods have been successfully used for directly determining ionic sweeteners due to its good

51 sensitivity, simple and inexpensive instrumentation and unrequired derivatization steps. For example, Bergamo et al

$52{ }^{29}$ determined four sweeteners in soft drinks and tabletop sweetener formulations by $\mathrm{CE}-\mathrm{C}^{4} \mathrm{D}$. A complete separation

53 of the analytes could be attained in less than $6 \mathrm{~min}$ and the method provided an excellent low limit of detection. The

54 prosed method shows $\mathrm{CE}-\mathrm{C}^{4} \mathrm{D}$ has a great potential in separation of ionic lacking UV-absorbing compounds.

55 However, for various food species with more complicated matrix, it is necessary to develop suitably sensitive and

56 reliable methods for determination of different sweeteners.

Considering the sweeteners' concentration are low, as well as coexistence components in complicated matrix

can interfere with the determination of sweeteners. Many sample pre-treatment techniques involving pressurised

liquid extraction (PLE) ${ }^{20}$, on-line preconcentration ${ }^{30}$ and solid phase extraction (SPE) ${ }^{16,18,21,22,25}$ were developed by

60 numerous researchers to purify and enrich analytes. Among these methods, SPE has been widely used because of its

61 simplicity, rapidity, low cost, and ability to combine with different detectors in both on-line and off-line mode. To

62 date, a number of commercially available SPE cartridges, such as Oasis HLB, CNW poly-sery PWAX, Oasis MAX

63 and Plexa PAX were introduced to isolate the sweeteners from different matrices $16,18,21,22,25$. However, these

64 commercial SPE absorbents have a limit in effectively extracting multiple targets from complex matrix due to its

65 single interaction mechanism. Therefore, there is considerable interest in developing new selective multi-interaction

66 sorbents for extracting and isolating sweeteners from complicated matrices. 
In recent years, porous materials stand out among numerous absorbents on account of their outstanding

performance in the sample pretreatment, especially porous aromatic frameworks (PAFs) which has larger surface area and larger $\pi-\pi$ conjugate system as well as a simple preparation procedure ${ }^{31,32}$. Our group has been committed to the research of COFs in recent years, and a novel multi-interaction and mixed-mode porous aromatic frameworks PAF-6 has been synthesized ${ }^{33}$ and used as SPE adsorbent to extract and determine bisphenol A (BPA) in milk and its packing samples. The results show that PAF-6 has an excellent adsorption capability for BPA based on hydrogen bonding and the inclusion interactions of host-guest. At the same time, the PAF-6 coated magnetic nanoparticles (PAF-6 MNPs) ${ }^{34}$ were prepared and used to enrich and remove the trace organic pollutants in water, and the main toxic component in mainstream smoke of cigarette, respectively. The results demonstrate that the PAF-6 MNPs sorbent possesses excellent adsorption of phenols, polycyclic aromatic hydrocarbons (PAHs) and nitroaromatics based on multiple $\pi-\pi$ stacking and hydrogen-bond interactions. According to the molecular structures of of PAF- 6 (Fig 1A) and ACE, SAC and CYC (Fig. 1B), it is suggested that the $p-p$ conjugate interactions, anion exchange interactions and inclusion complexations may exist between PAF-6 and these three sweeteners. Therefore, it is feasible to apply PAF-6 as SPE absorbent to purify and enrich them from foodstuffs before $\mathrm{CE}-\mathrm{C}^{4} \mathrm{D}$ analysis.

81 In this work, SPE procedure with PAF-6 as sorbent was optimized for effectively extracting and enriching three

82 sulfanilamide artificial sweeteners in foodstuffs. Gauss theoretical calculations were carried out to assistantly

83 elucidate the multi-interaction sites between PAF-6 and the sweeteners. Based on SPE clean-up procedure, CE-C ${ }^{4} \mathrm{D}$ 
84 method is developed for analysis of the three sulfanilamide artificial sweeteners in different beverage samples and

85 candied fruits with satisfactory results.

\section{Experimental}

Reagents and solutions

PAF-6 was synthesized in accordance with the previously published procedures ${ }^{33}$, Reagents were all of analytical grade. Tris(hydroxymethyl)aminomethane (Tris), Hexadecyl Trimethyl Ammonium Bromide (CTAB) and

90 Sodium tetraborate were purchased from Shanghai Chemical Reagent Company of China National Pharmaceutical

91 Group (Shanghai, China). ACE, SAC and CYC were purchased from Aldrich (Milwaukee, WI, USA). Deionized

92 water was obtained from a Milli-Q Water Purification System (Millipore, Bedford, MA). Individual stock solution (1

$93 \mathrm{mg} \mathrm{mL} \mathrm{m}^{-1}$ ) of each sweetener was prepared by dissolving the corresponding solid reagents in deionized water.

94 Standard solutions used in the analysis were prepared by dilution of the respective stock solutions with deionized

95 water, as required.

\section{Electrophoretic equipment and conditions}

99 the previous report ${ }^{35}$. The bare fused-silica capillaries were obtained from Yongnian Optical Fiber Corporation

100 (Hebei, China) with an inner diameter of $50 \mu \mathrm{m}$ and a length of $50 \mathrm{~cm}$ (41.5 $\mathrm{cm}$ to the detection window). The 
101 apparent $\mathrm{pH}$ was obtained by using a pH meter (Shanghai Weiye Factory, Shanghai, China). A buffer solution (pH

102 9.74) containing $20 \mathrm{mmol} \mathrm{L}{ }^{-1}$ Tris, $20 \mathrm{mmol} \mathrm{L}^{-1} \mathrm{Na}_{2} \mathrm{~B}_{4} \mathrm{O}_{7}$ and $50 \mu \mathrm{mol} \mathrm{L}^{-1} \mathrm{CTAB}$ were used as background

103 electrolyte (BGE) throughout this work. The separation voltage was $-20 \mathrm{kV}$ and the injection time was $5 \mathrm{~s}$ (at

104 50mbar). Before the analysis, the capillary was flushed with $1 \mathrm{~mol} \mathrm{~L}^{-1} \mathrm{NaOH}$ solution for 10 min, then with

105 deionized water for $15 \mathrm{~min}$, and finally with the BGE for $10 \mathrm{~min}$. After each run, the capillary was flushed with BGE

106 for $3 \mathrm{~min}$.

107 Sample preparation

108 A centrifuge (Zhongda Instrument Plant, Jiangsu, China) was used for centrifugal separation. All samples,

109 including 8 beverages ( 2 carbonated cola drinks, 3 fruit juice drinks, 1 red wine drink, 2 plum grape wine drinks), 6

110 candied fruits (2 candied mango, 2 candied plum, 2 candied kumquat) were purchased from local market (Zhengzhou,

111 China). They were prepared by the relevant procedures as follows.

112 For beverages, two carbonated cola drinks were degassed for $5 \mathrm{~min}$ in an ultrasonic bath, other six beverages

113 were shaken well. Then, they were diluted with deionized water as required. For candied fruits, take the edible part

114 of the candied fruits and mix homogeneously, a $5 \mathrm{~g}$ homogenized sample was dissolved in $20 \mathrm{~mL}$ of deionized water

115 and ultrasonicated in an ultrasonic bath for 10 minutes, and followed by centrifugation at 2100 rpm for 10 minutes.

116 The supernatant was transferred into a 50-mL volumetric flask. The precipitate was washed with deionized water and

117 repeated extraction. The supernatants were pooled into the same $50-\mathrm{mL}$ volumetric flask, and deionized water was 
118 added volumetrically to $50 \mathrm{~mL}$ level. All sample solutions prepared were stored at $4{ }^{\circ} \mathrm{C}$, then diluted as required for

119 SPE procedure.

120 PAF-6 SPE procedure

121 As shown in Fig. 2, $30 \mathrm{mg}$ of PAF-6 sorbent was packed into a $3 \mathrm{~mL}$ SPE cartridge. In total, $50 \mathrm{~mL}$ diluting

122 sample solution was passed through the PAF-6 SPE cartridge by gravity, which had been preconditioned with $3 \mathrm{~mL}$

123 of $\mathrm{MeOH}$ and $3 \mathrm{~mL}$ water, respectively. The cartridge was then washed with $3 \mathrm{~mL}$ water, and eluted with $5 \mathrm{~mL} 8 \%$

124 ammoniation ethanol. The eluate was evaporated at ambient temperature under a gentle stream of nitrogen gas until

125 dry and re-dissolved in $1 \mathrm{~mL}$ buffer. Each sample was filtered through a $0.22 \mu \mathrm{m}$ Nylon filter (Agilent, USA) prior

126 to $\mathrm{CE}-\mathrm{C}^{4} \mathrm{D}$ analysis. All tests were performed in triplicate.

\section{Quantum chemistry calculation}

To further understand the mechanism of molecular interactions between the PAF- 6 absorbent and target

129 analytes. Geometries of the guest ACE, SAC, CYC and the host PAF-6 were optimized by B3LYP/6-31+G(d) level.

130 The sizes of PAF-6 and the tree sweeteners were calculated using the Gaussian 09 program.

\section{Results and disscussion}

\section{Optimizing $C E-C^{4} D$ conditions}


135 with good resolution can be obtained in less than $8 \mathrm{~min}$.

136 The sensitivity of the conductivity detection is directly proportional to the mobility difference between the

137 analytes and the BGE co-ion; the BGE counter-ion also has influence on the instrument response. Moreover, BGE

138 significantly affects the migration time and the separation between targets directly. In the selection of BGE, the main

139 consideration is the ionization characteristic of the analytes. The pKa values for the corresponding acids of the ACE,

140 SAC and CYC are 2.0, 1.8 and 1.9, respectively, which indicated that the analytes have a net negative charge in an

141 aqueous BGE when $\mathrm{pH}>2.0$, and at $\mathrm{pH}$ above $4.0,>99 \%$ are in anionic form. Therefore, in our study, negative

142 polarity separation voltage was used. However, in negative polarity separation voltage mode, the direction of the

143 electroosmotic flow (EOF) was opposite to that of anion electromigration resulted in very poor resolution. So it is

144 favorable to use the EOF modifier to suppress or reverse EOF direction when $\mathrm{pH}>4.0$. Thus, we chose general

$145 \mathrm{CTAB}$ as the EOF modifier. Accordingly in the present work, several electrolytes utilized as the buffer solution that

146 possess a useful $\mathrm{pH}$ range from 3.0 to 10.0 were tested, including $\mathrm{Na}_{2} \mathrm{~B}_{4} \mathrm{O}_{7}, \mathrm{Na}_{2} \mathrm{~B}_{4} \mathrm{O}_{7}-\mathrm{H}_{3} \mathrm{BO}_{3}$, Tris-His, Tris- $\mathrm{H}_{3} \mathrm{BO}_{3}$

147 and Tris- $\mathrm{Na}_{2} \mathrm{~B}_{4} \mathrm{O}_{7}$. Among these tested $\mathrm{BGE}, 20 \mathrm{mM}$ Tris- $\mathrm{Na}_{2} \mathrm{~B}_{4} \mathrm{O}_{7}$ provided satisfactory results with the highest

148 resolution relative to the others.

149 The mixture of Tris and $\mathrm{Na}_{2} \mathrm{~B}_{4} \mathrm{O}_{7}$ is used for keeping the background conductivity as low as possible as well as

150 producing the necessary $\mathrm{pH}$ buffering. In order to further improve the separation of these three artificial sweeteners,

151 buffer $\mathrm{pH}$ and concentration of $\mathrm{Na}_{2} \mathrm{~B}_{4} \mathrm{O}_{7}$ in buffer were optimized. The relevant responses were evaluated by the

152 resolutions between ACE and SAC (Rs1) and between SAC and CYC (Rs2). According to the results in table 1, a 
153 BGE containing $20 \mathrm{mM} \mathrm{Na}_{2} \mathrm{~B}_{4} \mathrm{O}_{7}$, at $\mathrm{pH} 9.74$ adjusted by adding Tris was chosen because it provided the highest

154 resolution relative to the others.

155 Tests also showed that the efficiency of the separation became good and the migration time became short, when

156 the separation voltage was increased. As known, the higher voltage will result in the peak broadening because of the

157 Joule heating effect, the lower voltage will result in the poor resolution. Therefore, a voltage of - $20 \mathrm{kV}$ when the

158 analytes can observe the minor peak-broadening was selected as the best separation voltage in our study. In addition,

159 the introduction of an organic solvent into a buffer system was considered as a method for improving the separation

160 efficiency because the organic solvent would change the physicochemical nature of the separation system. However,

161 no obvious improvement was observed. So organic solvent will not be added

\section{Optimization of SPE procedure}

164 and volume of eluent) on the SPE recoveries ( $n=3)$ of ACE, SAC, CYC are evaluated in detail to obtain the optimal

165 extraction conditions using simulated samples.

Firstly, the efficiency of the PAF-6 amount on the recovery of analytes was studied. Five absorbent amounts 
experiments.

173 nitrogen character on piperazine of PAF-6 indicates that adsorption of sweeteners may be relative to weak anion

174 exchange interactions. So the alkaline environment is good to the process of elution. So we added ammonia into

175 eluent solvents. As is shown in Fig. 4B, three kinds of solutions (ammoniation acetonitrile, ammoniation methanol

176 and ammoniation ethanol) all can yield good recoveries. Taking environment protection into account, we chose

177 ammoniation ethanol as eluent solvent.

178 We subsequently optimized the content of $\mathrm{NH}_{3} \cdot \mathrm{H}_{2} \mathrm{O}$ in ammoniation ethanol. The obtained results (Fig. 4C)

179 showed that $8 \%$ ammoniation ethanol yielded the highest recovery. Therefore, the content of $\mathrm{NH}_{3} \cdot \mathrm{H}_{2} \mathrm{O}$ need to be

180 adjusted $8 \%$ in the actual determination.

181 In addition, various volumes $(1-9 \mathrm{~mL})$ of ammoniation ethanol were used for the PAF-6 SPE process. The

182 results (Fig. 4D) showed that when the eluent volume reached $5 \mathrm{~mL}$, the value of recovery was higher than $90 \%$.

183 When the eluent volume was more than $5 \mathrm{~mL}$, the recoveries of sweeteners remained almost constant. Taking

184 reagent saving into account, $5 \mathrm{~mL}$ ammoniation ethanol was chosen in this study.

\section{Retention mechanism discussion based on quantum chemistry calculations}

186 PAF-6 demonstrated significant enhanced adsorption ability for ACE, SAC and CYC, indicating the crucial 


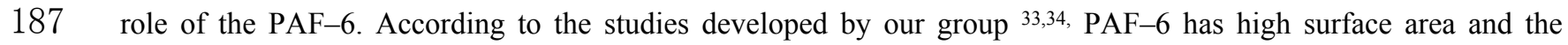

188 NLDFT pore size distribution exhibited broad mesoporosity $(2-5 \mathrm{~nm})$ in its framework. So inclusion complexation

189 should be considered during the process of adsorption. From the results (Fig. 1C) calculated using Gaussian 09

190 program, it can be seen obviously that the inclusion complexation existed in host (PAF-6)-guests (ACE, SAC, CYC)

191 as the sizes of ACE, SAC and CYC are much smaller than that of the channel of PAF-6.

\section{Method validation}

\section{Linearity, detection limits, and precision}

The method validation including linearity range, LODs, LOQs and precision was carried out, and were

195 summarized in Table 2. There was an excellent linearity between the peak area $(\mathrm{mV})$ and the concentration of ACE,

196 SAC in the range of $0.5-25 \mu \mathrm{M}$ and CYC in the range of $1-50 \mu \mathrm{M}$ with the correlation coefficients from 0.9949 to

197 0.9973. For the LOD, a signal-to-noise ratio of 3 was evaluated. The LODs were $0.09 \mu \mathrm{M}, 0.12 \mu \mathrm{M}$ and $0.22 \mu \mathrm{M}$,

198 respectively, which were all less than LOD of CZE-UV and common CE-C ${ }^{4} \mathrm{D}$. For the LOQ, a signal-to-noise ratio

199 of 10 was evaluated. The LOQs were $0.32 \mu \mathrm{M}, 0.37 \mu \mathrm{M}$ and $0.75 \mu \mathrm{M}$, which were all less than the maximum

200 regulatory limits. The inter-day and intra-day analysis precision was tested at $1 \mu \mathrm{M}$ levels, RSDs were found below

$2014.3 \%(n=6)$, indicating good repeatability.

\section{Accuracy and recovery test}

203 To further evaluate the reliability of this proposed method, Recovery experiments were performed by adding 
204 accurate amounts of ACE, SAC and CYC to the real samples. The standard-spiked samples were subject to the same

205 sample preparation procedure as the real samples. As presented in Table 3, the average recovery data at three

206 different concentrations were in the range of $78.89-92.00 \%$ with corresponding RSDs of $1.90-3.91 \%$. From these

207 results, it was concluded that the developed method was accurate, reproducible and reliable for analysing ACE, SAC

208 and CYC in beverage samples and candied fruits.

\section{Analyses of real samples}

211 with RSD values lower than 5\%. Typical chromatograms of orange juice drink and candied mango A before and

212 after SPE were shown in Figure 5. It is obviously observed that the matrix interference can be minimized after

213 purification using the PAF-6 SPE sorbent, and meanwhile targets achieved enrichment. The results indicated that the

214 developed method was suitable for the determination of the three artificial sweeteners in beverage samples and

215 candied fruits.

\section{Comparison of proposed method with previously reported results}

To evaluate the analytical performance of the proposed method, a comprehensive comparison of the proposed

218 method with other reported methods for determination of artificial sweeteners is presented in Table 5. As could be

219 observed, the proposed method can directly accomplish the determination of these three sweeteners without

220 derivation. And it reduced matrix interference as well as provided a low LOD after a SPE clean-up procedure. At the 
221 same time, the prosed method was time saving and cost-effective, it was demonstrated to be rapid, simple, cheap and

222 sensitive for determination of artificial sweeteners in beverage samples and candied fruits.

\section{Conclusion}

225 determination of three high-intensity sweeteners in beverage samples and candied fruits. For the first time, a novel

226 home-made multiple-interaction SPE absorbent PAF-6 was used to purify and enrich these sweeteners in foodstuffs

227 containing complicated matrices. By using the SPE pretreatment technique, matrix interference is minimized and

228 excellent detection limits can be achieved, these were much lower than those normal CZE-UV and CE-C ${ }^{4} \mathrm{D}$ methods.

229 The method is suitable for use by the food industry for quality control as well as by health and safety agencies for

230 inspections. We also believe that the SPE-CE- $\mathrm{C}^{4} \mathrm{D}$ method can easily be used for analysis of other matrices, such as

231 teas, ice cream, desserts and other foods.

232 Acknowledgements The authors acknowledge the support of National Natural Science Foundation of China

$233(21475119,21775140)$.

\section{Compliance with Ethical Standards}

235 Funding This study was funded by the National Natural Science Foundation of China (No. 214751119 and

236 21775140).

237 Conflict of interest All authors declare that they have no conflict of interest. 
238 Ethical approval This article does not contain any studies with human participants or animals performed by any of

239 the authors. 


\section{$241 \quad$ References}

242 (1) Sardesai, V. M.; Waldshan, T. H. J. Nutr. Biochem 1991, 2, 235. doi: 10.1016/0955-2863(91)90081-F.

243 (2) Shankar, P.; Ahuja, S.; Sriram, K. Nutrition 2013, 29, 1293. doi: 10.1016/j.nut.2013.03.024.

244 (3) Bandyopadhyay, A.; Ghoshal, S.; Mukherjee, A. Drug and chemical toxicology 2008, 31, 447. doi:

$245 \quad 10.1080 / 01480540802390270$.

(4) Burke, M. V.; Small, D. M. Physiology \& behavior 2015, 152, 381. doi: 10.1016/j.physbeh.2015.05.036.

(5) FAO \& WHO (2006) Summary of Evaluations Performed by the Joint FAO/WHO Expert Committee on Food Additives (JECFA) 1956-2007 (First through sixtyeighth meetings)

(6) Renwick, A. G. Food Addit. Contam 2006, 23, 327. doi: 10.1080/02652030500442532.

(7) Mortensen, A. Scandinavian Journal of Food and Nutrition 2016, 50, 104. doi: : $10.1080 / 17482970600982719$.

(8) GB2760-1996 (1996). Hygienic Standards for Uses of Food Additives. National Standard of the People's

Republic of China

(9) Lee, Y.; Do, B.; Lee, G.; Lim, H. S.; Yun, S. S.; Kwon, H. Food additives \& contaminants. Part A, Chemistry, analysis, control, exposure \& risk assessment 2017, 34, 666. doi: 10.1080/19440049.2017.1284348. 
(11) Sargaco, B.; Serra, C.; Vasco, E. Food additives \& contaminants. Part A, Chemistry, analysis, control, exposure \& risk assessment 2017, 34, 883. doi: 10.1080/19440049.2017.1306756.

(12) Zhu, Y.; Guo, Y.; Ye, M.; James, F. S. Journal of Chromatography A 2005, 1085, 143. doi: 10.1016/j.chroma.2004.12.042.

(13) Chen, Q.; Mou, S.; Liu, K.; Yang, Z.; Ni, Z. Journal of Chromatography A 1997, 771, 135.doi: 10.1016/S0021-9673(97)00067-8.

(14) Hashemi, M.; Habibi, A.; Jahanshahi, N. Food Chemistry 2011, 124, 1258. doi: 10.1016/j.foodchem.2010.07.057.

(15) Yu, S.; Zhu, B.; Lv, F.; Li, S.; Huang, W. Food Chem 2012, 134, 2424. doi: 10.1016/j.foodchem.2012.04.028.

(16) Gan, Z.; Sun, H.; Wang, R.; Feng, B. Journal of chromatography. A 2013, 1274, 87. doi: 10.1016/j.chroma.2012.11.081.

(17) Scheurer, M.; Brauch, H. J.; Lange, F. T. Analytical and bioanalytical chemistry 2009, 394, 1585. doi: $10.1007 / \mathrm{s} 00216-009-2881-\mathrm{y}$. 10.1016/j.chroma.2012.07.073. 
(19) Sakai, H.; Yamashita, A.; Tamura, M.; Uyama, A.; Mochizuki, N. Food additives \& contaminants. Part A,

(20) Ordonez, E. Y.; Quintana, J. B.; Rodil, R.; Cela, R. Journal of chromatography. A 2013, 1320, 10. doi: 10.1016/j.chroma.2013.10.049.

(21) Loos, R.; Gawlik, B. M.; Boettcher, K.; Locoro, G.; Contini, S.; Bidoglio, G. Journal of chromatography. A 2009, 1216, 1126. doi: 10.1016/j.chroma.2008.12.048.

(22) Arbelaez, P.; Borrull, F.; Pocurull, E.; Marce, R. M. Journal of chromatography. A 2015, 1393, 106. doi: 10.1016/j.chroma.2015.03.035.

(23) Lim, H. S.; Choi, E.; Hwang, J. Y.; Lee, G.; Yun, S. S.; Kim, M. Food additives \& contaminants. Part A, Chemistry, analysis, control, exposure \& risk assessment 2018, 35, 1674 . doi: 10.1080/19440049.2018.1486043. 10.1016/0021-9673(95)00210-E.

(25) Horie, M.; Ishikawa, F.; Oishi, M.; Shindo, T.; Yasui, A.; Ito, K. Journal of chromatography. A 2007, 1154, 423. doi: 10.1016/j.chroma.2007.03.094. 
289 (27) Vistuba, J. P.; Dolzan, M. D.; Vitali, L.; de Oliveira, M. A.; Micke, G. A. Journal of chromatography. A 2015,

$290 \quad$ 1396, 148. doi: 10.1016/j.chroma.2015.03.070.

291 (28) Bergamo, A. B.; Fracassi da Silva, J. A.; de Jesus, D. P. Food Chemistry 2011, 124, 1714. doi: $292 \quad$ 10.1016/j.foodchem.2010.07.107.

293 (29) Stojkovic, M.; Mai, T. D.; Hauser, P. C. Analytica chimica acta 2013, 787, 254. doi: $294 \quad$ 10.1016/j.aca.2013.05.039.

295 (30) Yang, L.; Zhou, S.; Xiao, Y.; Tang, Y.; Xie, T. Food Chem 2015, 188, 446. doi: $296 \quad$ 10.1016/j.foodchem.2015.04.060.

297 (31) Díaz, U.; Corma, A. Coordination Chemistry Reviews 2016, 311, 85. doi: 10.1016/j.ccr.2015.12.010.

298 (32) Qian, H. L.; Yang, C. X.; Wang, W. L.; Yang, C.; Yan, X. P. Journal of chromatography. A 2018, 1542, 1. doi:

$299 \quad$ 10.1016/j.chroma.2018.02.023.

300

301

(33) Yin, D.; Chen, Y.; Zhang, Y.; Yang, Z.; Mao, H.; Xia, S.; Zhang, W.; Zhao, W.; Zhang, S. Chromatographia 2018, 81, 749. doi: 10.1007/s10337-018-3504-6.

(34) Chen, Y.; Zhang, W.; Zhang, Y.; Deng, Z.; Zhao, W.; Du, H.; Ma, X.; Yin, D.; Xie, F.; Chen, Y.; Zhang, S. 
304 (35) Zhao, S.; Yin, D.; Du, H.; Tian, X.; Chen, Y.; Zhang, W.; Yu, A.; Zhang, S. Journal of separation science 2018,

305 41, 2623. doi: 10.1002/jssc.201701432.

306 


\section{Figure captions}

308 Fig.1 Chemical structures of (A) PAF-6 and (B) three sulfanilamide artificial sweeteners and (C) optimized

309 geometries of the host (PAF-6)-guests (ACE, SAC, CYC) based on inclusion complexations.

310 Fig.2 Schematic representation of the solid phase extraction of three sulfanilamide artificial sweeteners in foodstuffs

311 followed by $\mathrm{CE}-\mathrm{C}^{4} \mathrm{D}$.

312 Fig.3 Electropherogram of standard solution containing $1 \mu \mathrm{M}$ of each sweetener with SPE-CE-C ${ }^{4} \mathrm{D}$. Peak

313 identification: 1, ACE; 2, SAC; 3, CYC.

314 Other conditions: BGE: 20 mmol L-1 Tris $+20 \mathrm{mmol} \mathrm{L}^{-1} \mathrm{Na}_{2} \mathrm{~B}_{4} \mathrm{O}_{7}+50 \mu \mathrm{mol} \mathrm{L}^{-1} \mathrm{CTAB}$. Separation voltage: - $20 \mathrm{kV}$;

315 Pressure injection: $50 \mathrm{mbar} \times 5 \mathrm{~s}$; silica capillary with $50 \mu \mathrm{m}$ inner diameter and $50 \mathrm{~cm}$ length $(41.5 \mathrm{~cm}$ effective).

316 Fig.4 SPE optimization for three sulfanilamide artificial sweeteners with the PAF-6 sorbent. (A) influnce of PAF-6

317 amount; (B) influnce of different kinds of eluent solvents on the recovery; (C) influence of different content of

$318 \mathrm{NH}_{3} \cdot \mathrm{H}_{2} \mathrm{O}$ in eluent on the recovery; (D) influence of different eluent volumes on the recovery.

319 Fig.5 Electropherograms of real samples. (A) orange juice drink, and (B) candied mango A with (a) homemade

320 PAF-6 sorbent and (b) without SPE. 


\section{Tables}

2 Table 1 The effect of buffer $\mathrm{pH}$ and buffer concentration on separation degree.

\begin{tabular}{cccc}
\hline $\begin{array}{c}\mathrm{Na}_{2} \mathrm{~B}_{4} \mathrm{O}_{7} \text { Concentration in } \\
\mathrm{BGE}(\mathrm{mmol} / \mathrm{L})\end{array}$ & $\mathrm{pH}$ & $\mathrm{Rs} 1$ & Rs2 \\
& & $(\mathrm{ACE} / \mathrm{SAC})$ & $(\mathrm{SAC} / \mathrm{CYC})$ \\
15 & 9.59 & 2.17 & 6.29 \\
10 & 9.63 & 2.33 & 6.74 \\
20 & 9.74 & 2.96 & 6.88 \\
25 & 9.79 & & 6.37 \\
\hline
\end{tabular}

3 
4 Table 2 Figures of merit for the ACE, SAC and CYC, based on the areas of the peaks recorded at the CE-C $\mathrm{C}^{4} \mathrm{D}$ 5 detector ( $\mathrm{Y}$ and $\mathrm{X}$ are expressed in $\mathrm{mV}$ and $\mu \mathrm{M}$, respectively).

\begin{tabular}{|c|c|c|c|c|c|c|c|}
\hline \multirow[t]{2}{*}{ Analytes } & \multirow{2}{*}{$\begin{array}{c}\text { Regression } \\
\text { equation }\end{array}$} & \multirow{2}{*}{$\begin{array}{c}\text { Evaluated range } \\
(\mu \mathrm{M})\end{array}$} & \multirow{2}{*}{$\begin{array}{c}\text { Coefficient of } \\
\text { determination, } \mathrm{R}^{2}\end{array}$} & \multirow{2}{*}{$\begin{array}{l}\text { LOD } \\
(\mu \mathrm{M})\end{array}$} & \multirow{2}{*}{$\begin{array}{l}\text { LOQ } \\
(\mu \mathrm{M})\end{array}$} & \multicolumn{2}{|c|}{$\operatorname{RSD}(\%)(\mathrm{n}=6)$} \\
\hline & & & & & & Intraday & interday \\
\hline ACE & $y=108.71 x+8.573$ & $0.5-25$ & 0.9973 & 0.09 & 0.32 & 3.2 & 3.9 \\
\hline SAC & $y=169.22 x-5.835$ & $0.5-25$ & 0.9961 & 0.12 & 0.37 & 3.7 & 4.1 \\
\hline $\mathrm{CYC}$ & $y=223.01 x-17.63$ & $1-50$ & 0.9949 & 0.22 & 0.75 & 2.9 & 4.3 \\
\hline
\end{tabular}


Table 3 Recoveries of spiked-standard in real samples.

\begin{tabular}{|c|c|c|c|c|c|c|c|c|c|c|}
\hline \multirow{3}{*}{$\begin{array}{c}\text { Analyt } \\
\text { es }\end{array}$} & \multirow{3}{*}{$\begin{array}{l}\text { Spiked } \\
(\mu \mathrm{g} / \mathrm{g})\end{array}$} & \multicolumn{3}{|c|}{ Cola drink A } & \multicolumn{3}{|c|}{ Orange juice drink } & \multicolumn{3}{|c|}{ Candied mango $\mathrm{A}$} \\
\hline & & \multirow{2}{*}{$\begin{array}{l}\text { Found } \\
(\mu \mathrm{g} / \mathrm{g})\end{array}$} & \multirow{2}{*}{$\begin{array}{c}\text { Recovery } \\
(\mu \mathrm{g} / \mathrm{g})\end{array}$} & \multirow{2}{*}{$\begin{array}{l}\text { RSD } \\
(\%)\end{array}$} & \multirow{2}{*}{$\begin{array}{l}\text { Found } \\
(\mu \mathrm{g} / \mathrm{g})\end{array}$} & \multirow{2}{*}{$\begin{array}{c}\text { Recovery } \\
(\mu \mathrm{g} / \mathrm{g})\end{array}$} & \multirow{2}{*}{$\begin{array}{l}\text { RSD } \\
(\%)\end{array}$} & \multirow{2}{*}{$\begin{array}{c}\text { Found } \\
(\mu \mathrm{g} / \mathrm{g})\end{array}$} & \multirow{2}{*}{$\begin{array}{c}\text { Recovery } \\
(\mu \mathrm{g} / \mathrm{g})\end{array}$} & \multirow{2}{*}{$\begin{array}{l}\text { RSD } \\
(\%)\end{array}$} \\
\hline & & & & & & & & & & \\
\hline & 100 & 262.31 & 88.02 & 2.58 & 194.06 & 86.96 & 2.18 & 191.28 & 79.88 & 2.33 \\
\hline \multirow[t]{3}{*}{ ACE } & 200 & 332.07 & 78.89 & 1.99 & 291.11 & 92.00 & 2.25 & 277.83 & 83.21 & 2.08 \\
\hline & 500 & 600.77 & 85.30 & 2.92 & 559.66 & 90.51 & 2.63 & 561.45 & 90.01 & 2.86 \\
\hline & 100 & 211.73 & 84.32 & 2.78 & 87.20 & 87.20 & 2.33 & 152.79 & 81.28 & 3.91 \\
\hline \multirow[t]{3}{*}{ SAC } & 200 & 292.86 & 82.73 & 3.31 & 177.68 & 88.84 & 1.90 & 244.32 & 86.40 & 3.18 \\
\hline & 500 & 538.99 & 82.32 & 2.85 & 455.00 & 91.00 & 2.59 & 512.37 & 88.17 & 3.72 \\
\hline & 100 & 193.97 & 80.70 & 3.55 & 90.26 & 90.26 & 3.22 & 80.18 & 80.18 & 2.91 \\
\hline \multirow[t]{2}{*}{ CYC } & 200 & 282.91 & 84.82 & 2.84 & 175.96 & 87.98 & 3.90 & 172.84 & 86.42 & 2.30 \\
\hline & 500 & 512.25 & 79.80 & 2.69 & 458.97 & 91.79 & 2.28 & 427.95 & 85.59 & 3.55 \\
\hline
\end{tabular}


9 Table 4 Assay results of three sulfanilamide artificial sweeteners in real samples $(n=3)$.

\begin{tabular}{|c|c|c|c|}
\hline \multirow[t]{2}{*}{ Samples } & \multicolumn{3}{|c|}{ Average concentration detected $(\mu \mathrm{g} / \mathrm{g})$} \\
\hline & ACE & SAC & $\mathrm{CYC}$ \\
\hline Cola drink A & $174.29 \pm 0.45$ & $127.41 \pm 0.28$ & $113.27 \pm 0.40$ \\
\hline Cola drink B & $175.02 \pm 0.43$ & $240.26 \pm 0.55$ & $640.59 \pm 1.55$ \\
\hline Orange juice drink & $107.10 \pm 0.38$ & n.d. & n.q. \\
\hline Blueberry juice drink & $67.66 \pm 0.25$ & n.d. & $245.40 \pm 1.14$ \\
\hline Grape juice drink & $19.64 \pm 0.09$ & n.d & $283.15 \pm 0.85$ \\
\hline Red wine & n.d. & n.d. & n.d. \\
\hline Plum grape wine A & $8.51 \pm 0.03$ & n.d. & $123.56 \pm 0.34$ \\
\hline Plum grape wine B & $7.28 \pm 0.02$ & n.q & $131.29 \pm 0.33$ \\
\hline Candied mango A & $111.40 \pm 0.32$ & $71.51 \pm 0.18$ & n.q. \\
\hline Candied mango B & $120.20 \pm 0.35$ & n.d. & n.q. \\
\hline Candied plums A & $49.11 \pm 0.16$ & n.q. & $87.82 \pm 0.29$ \\
\hline Candied plums B & $51.25 \pm 0.17$ & n.q. & $621.18 \pm 1.43$ \\
\hline Candied kumquat A & $60.61 \pm 0.23$ & n.d. & n.d. \\
\hline Candied kumquat B & $70.36 \pm 0.18$ & n.q. & n.d. \\
\hline
\end{tabular}

10 Note: n.d. = not detected (below LOD); n.q. = detected but not quantified (concentration below LOQ). 


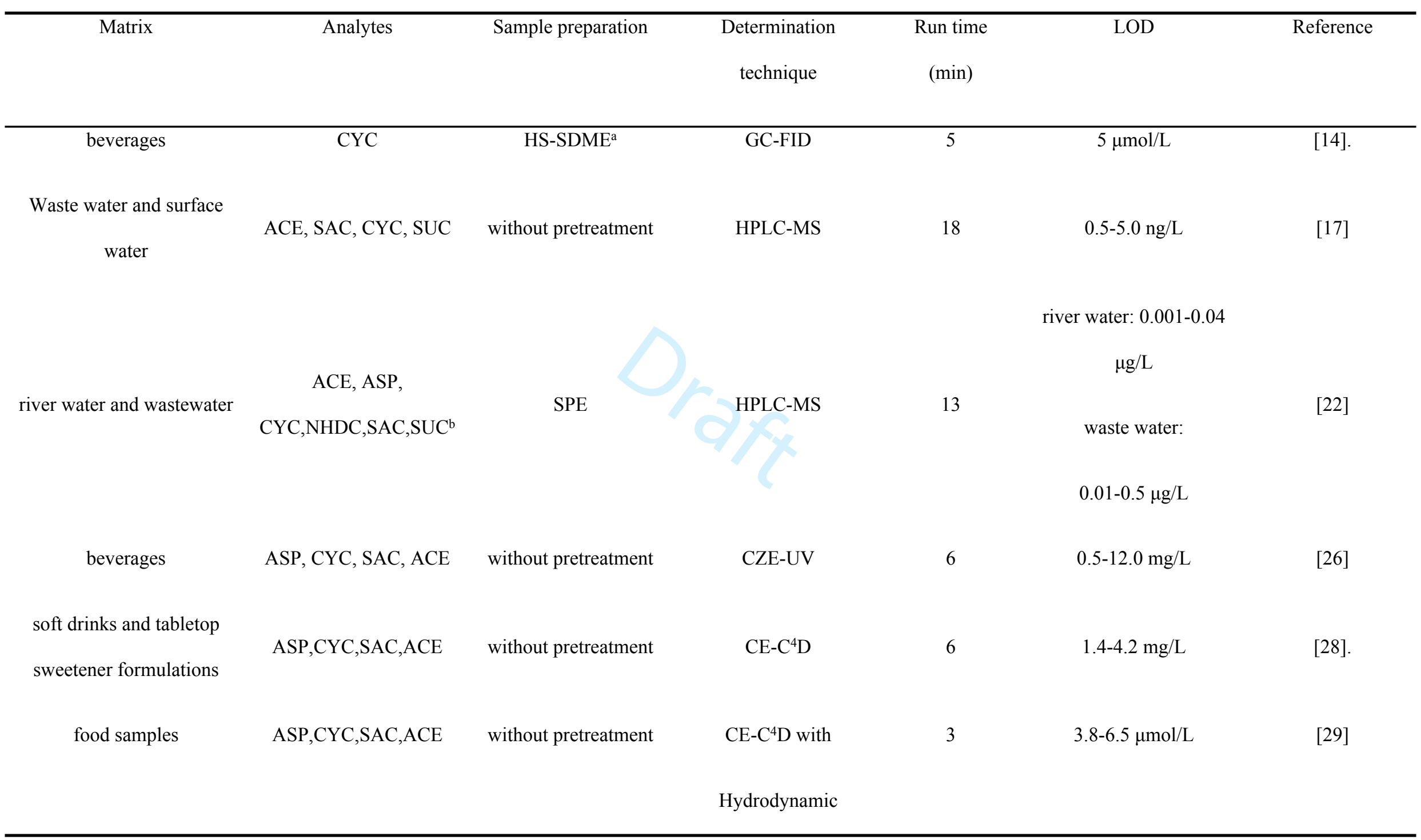


pumping

Beverages and candied

fruits

CE-C ${ }^{4} \mathrm{D}$

8

12 Table 5. Comparison of different methods for the determination of artificial sweeteners.

13 Note: aHS-SDME, headspace single-drop microextraction; ${ }^{b}$ ACE: acesulfame-K; ASP: aspartame; CYC: sodium cyclamate; NHDC: neohesperidin

14 dihydrochalcone; SAC: sodium saccharin; SUC, sucralose. 
Figure 1

(A)

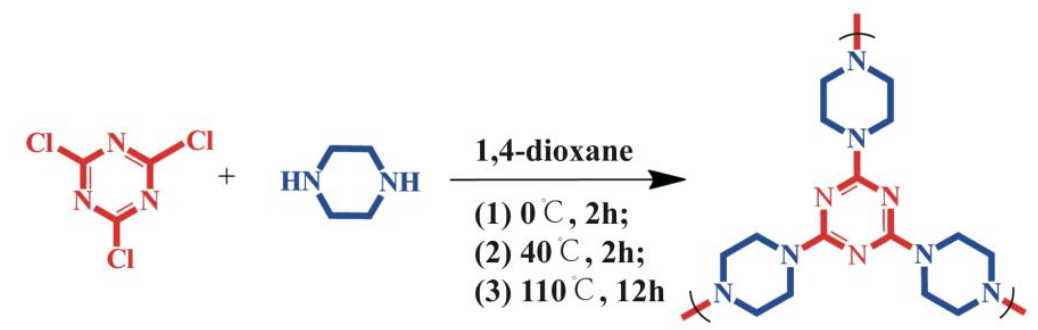

Synthetic procedure of PAF-6 sorbent

(B)<smiles>CC1=CC(=O)[NH+]([18F])S(=O)(=O)O1</smiles><smiles></smiles><smiles>O=S(=O)(NC1CCCCC1)O[Na]</smiles>
Acesulfame-K (ACE) pKa:2.0

Sodium saccharin (SAC) pKa:1.8

Sodium cyclamate (CYC) pKa:1.9

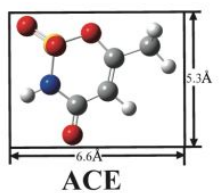

(C)
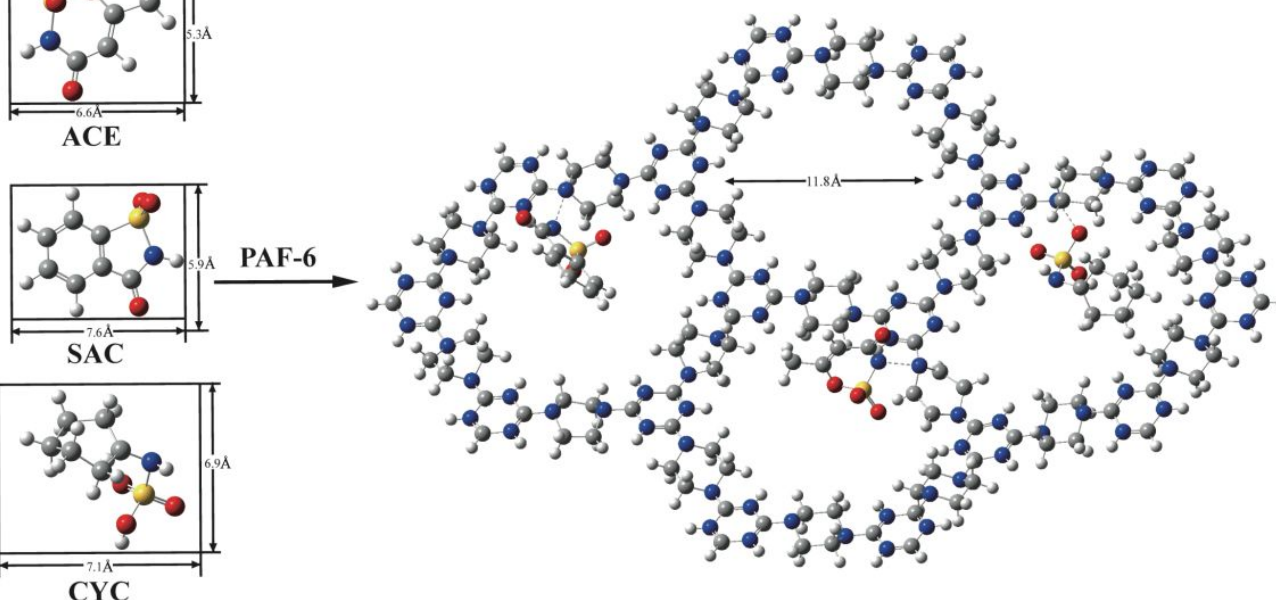

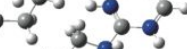
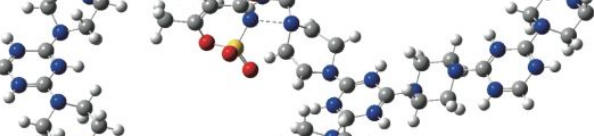

- 3 $20,3,00$,

Optimized geometries of the host (PAF-6)-guests (ACE, SAC, CYC) based on inclusion complexation 


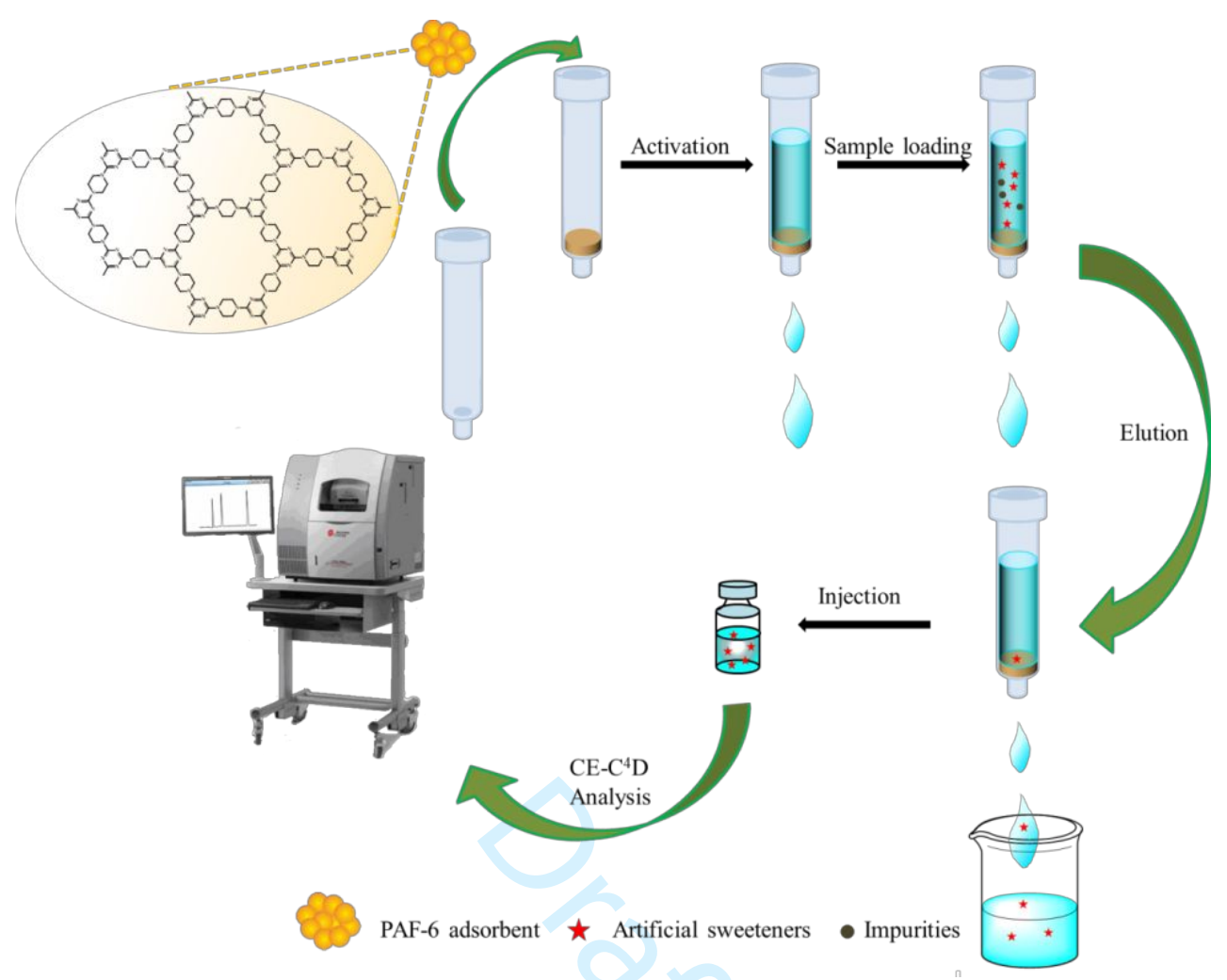


Figure 3

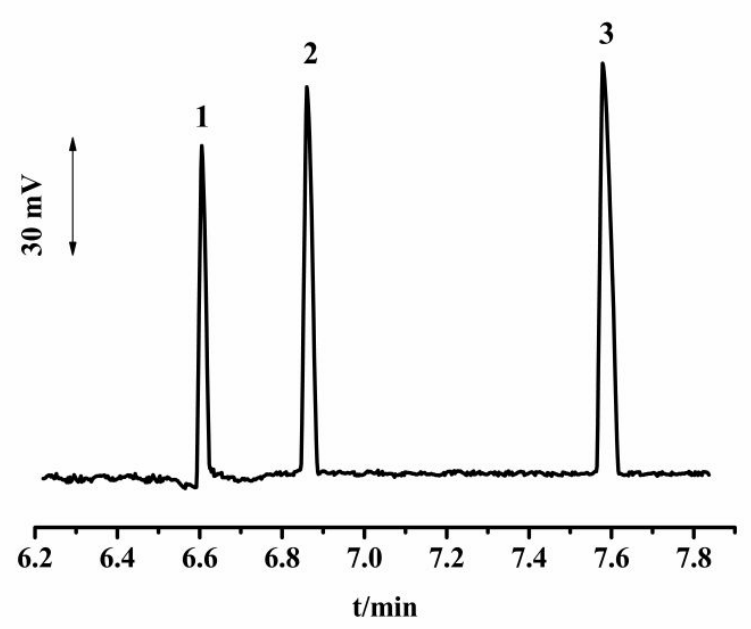



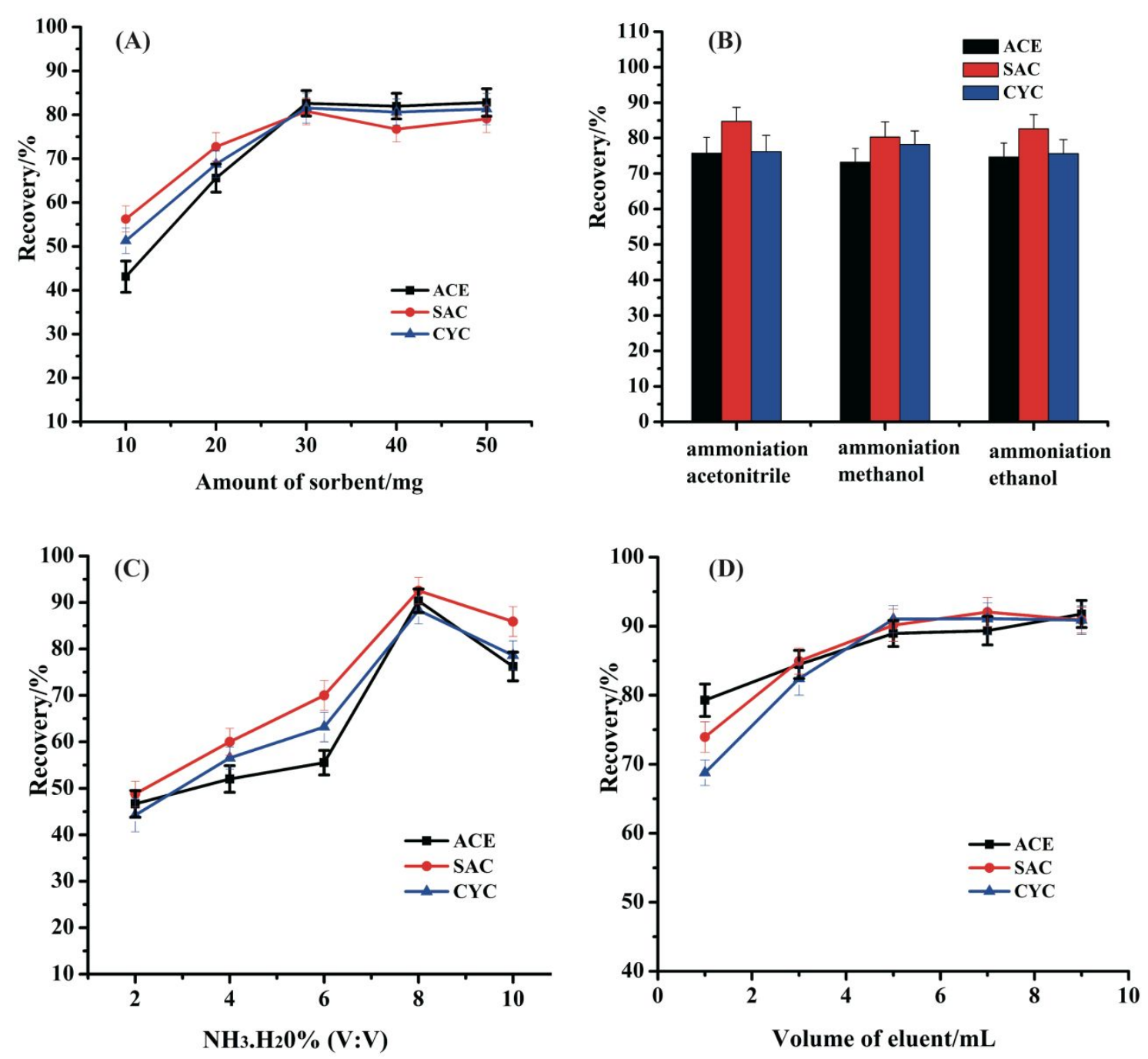
Figure 5

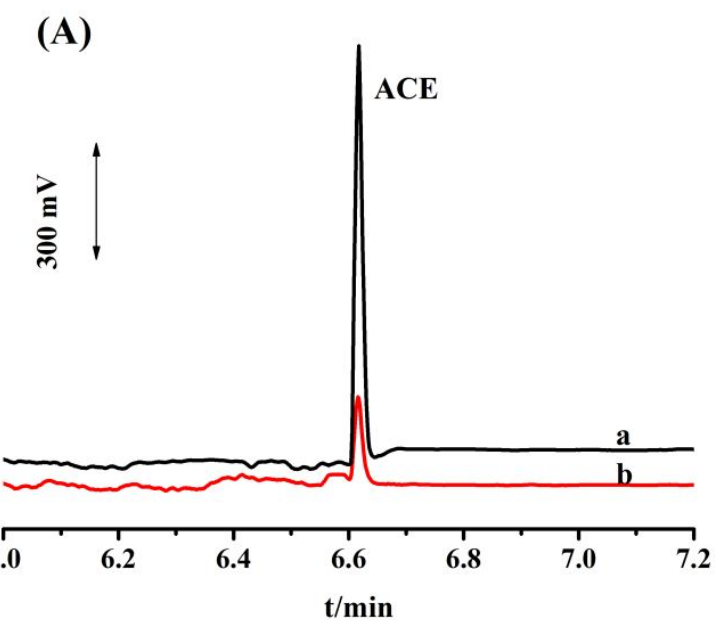

(B)

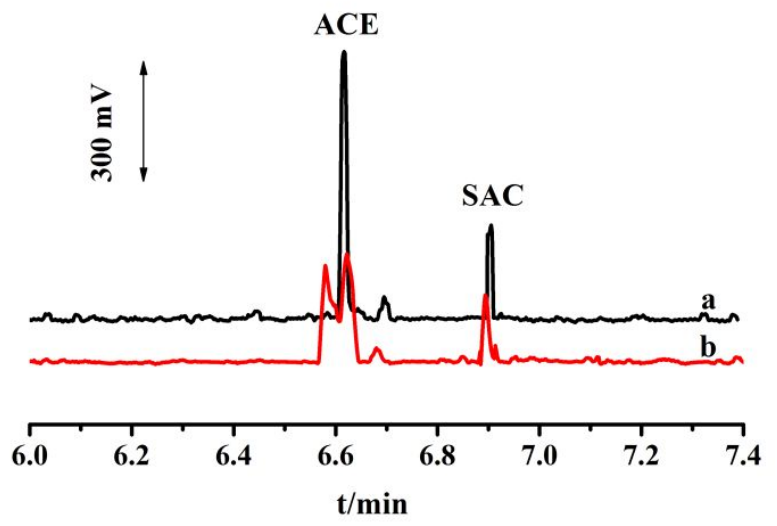

